\title{
Developing Productive Skills through an Interactive Approach: Present to Learn
}

\author{
Marine Milad ${ }^{1, *}$ \\ ${ }^{1}$ English Language and Applied Linguistics, Arab Open University, Kuwait Branch, Kuwait \\ *Corresponding author: English Language and Applied Linguistics, Arab Open University, \\ Kuwait Branch, Kuwait. E-mail: marinemilad@yahoo.com
}

Received: December 31, 2019 Accepted: September 12, 2020 Published: November 2, 2020

doi:10.5296/ije.v12i4.17898 URL: http://dx.doi.org/10.5296/ije.v12i4.17898

\begin{abstract}
This paper aims at presenting an interactive approach that was implemented on Arab Open University (AOU) students to enrich their productive skills namely speaking, oral presentation and writing skills. The researcher aimed at establishing a community of practice through a blended learning environment which considers non-traditional multicultural leaner. This community of practice presents a combination of face-to-face facilitated learning, e-learning and self-study. The researcher applied "Present to Learn" approach on AOU students employing Johari Windows Model to develop the identified productive skills and break the students' stage fright through collaboration in groups. An observation checklist was developed to check the students' oral presentation and writing prompts. In addition, a questionnaire was developed to measure the students' satisfaction towards the applied interactive approach and their assessment of the whole experiment. It was observed that cooperative work especially with having critical partners has improved the students' performance achievement through learning from each other in one group and competing with other groups. The collected feedback from the questionnaire was in favour of applying this approach on more groups which was implemented across three consecutive academic semesters. Moreover, the students' end results were statistically analysed and a correlation between high performance achievement and active participation inside and outside the class was drawn. The results have shown that students who participated by giving presentations reflecting their group work obtained higher grades than those who failed to work with others or did not give any presentations.
\end{abstract}

Keywords: interactive approach, present to learn, cooperative learning 


\section{Introduction}

Working in an open university which adopts the blended learning approach and has a grown number of non-traditional multicultural learners necessitates paying a significant consideration for such type of unique learners especially when designing learning environments. This has caused a fundamental educational question to be asked "how learning resources have traditionally been supplied to students, as against how they should now be supplied" (Bradwell, 2009). To answer this question, "Present to Learn" approach was implemented as a collaborative interactive method for enhancing the students' academic performance and developing their productive skills employing Johari Windows Model. A model for group cooperative learning which highlights the impact of the Internet on social interaction where students learn (theory), critique (current issues), explore (methods), and reflect (practice). Multiple learning dimensions were considered when the students first experience knowledge as 'Open' to self and others, second 'Blind' when only the other can see it, third 'Hidden' when it is known only to ourselves and finally 'Unconscious/Incidental' when it is unknown to self and others. The model's windows helped the students to promote and enhance their oral and written productive skills though communicating their knowledge to others, exchanging ideas, exploring new aspects of a given topic and recording their findings in written prompts.

\subsection{Interactive Approach}

Bradwell (2009) states that "teachers and lecturers have to deal with a much greater range of information processing styles, cultural backgrounds and styles of learning. As a result, the ideal for teaching in higher education is now recognised to involve much more than lectures as the means of information provision" (p. 19). This necessitates adapting a blend of different teaching methods where the tutor becomes a lecturer, demonstrator, facilitator, coach and delegator to accommodate the multicultural non-traditional learners of higher education. This would create an interactive learning environment that is learner-centred where learners become active participants in the learning process rather than passive recipients. Knowles (2005) advocated the word "Andragogy" which focuses on adult learning strategies and centres attention on the process of engaging adult learners within the structure of the learning experience. To engage adult learners, educators should encourage them to take the responsibility of their learning, provide them with the necessary educational tools and resources, and inspire them to draw from prior experience and build on background knowledge.

Paul and Mark (2002) state that adopting an interactive approach in higher education promotes group discussion and reflective feedback as core activities in any course material based on the Structure of the Observed Learning Outcome (SOLO) taxonomy. They applied the five stages of SOLO taxonomy (pre-structural, uni-structural, multi-structural, relational, and extended abstract) to describe their students' level of increasing complexity in understanding a subject. These stages helped the students make connections, generalizations and transference of the principles not only within the field of study, but also beyond it. They concluded that the use of group discussion and significant reflective practice not only 
enhanced interpersonal skills but also encouraged a deep approach to learning, leading to ownership of knowledge and increased awareness of the worth of field of study.

\section{2 "Present to Learn"}

Lecturing, memorization and teaching for exams never help students understand principles. Vygotsky (1986, p.117) claimed "the one who does the talking, does the learning." This saying is supported by another saying "Teaching is Learning." Most educators support this idea since learning usually takes place when the learner is personally engaged in the learning process.

Being engaged means being responsible for one's own learning and peers' learning as well. Research indicates that encouraging learning by teaching would help learners retain information longer especially when given the opportunity to realize, internalize and criticize ideas and solutions based on their own understanding (Picciano, 2009).

"Present to Learn" is an approach which applies learning by doing to get students practice the best way of gaining mastery of a certain subject or concept. Productive skills mainly speaking and writing skills can be enhanced through such approach by applying brainstorming, open discussion and interactive writing. Interactive writing is a cooperative experience in which text is jointly composed and written by a group of students monitored by their tutor. Swartz et al. (2001, p. 96) defined it as "a teaching method in which students and teacher negotiate what they are going to write and then share the pen to construct the message." In this approach the tutor(s) and students write to each other, by means of letters, dialogue journals or a message board. The students are free to choose the topic and the length of their writings and the teachers respond without correcting or criticizing the spelling, grammar or writing style, but rather modelling more appropriate forms of writing.

Presentations are characterised by being a verbal, sensory, visual and experiential mode of communication. Thus, giving presentations gives the students the opportunity to discuss, think, reflect, experience and intellectualise the presented topic. They can use their preferred tool to deliver a topic of their choice using visual descriptions such as colour words, audio, videos, pictures, role-plays, etc. Moreover, they should use power words, stories, sayings and examples to support their point. To implement such approach the researcher adapted Johari's Windows to get the students to work cooperatively in groups applying an interactive writing approach to design posters, charts or slides for their class presentations.

\subsection{Johari Window Model}

Johari Window is a model for group cooperative learning, named after Joseph Luft and Harry Ingham (1984) by combining the first syllable of their first names 'Jo' and 'Hari'. They developed this model to help people better understand their relationships with self and others. The model aimed at understanding the communication process (Luft, 1984). The Johari Window model categorizes degree of self-awareness and openness in communication into: (1) information known to self and others (open), (2) information known to self but not to others (hidden), (3) information known to others but not self (blind), and (4) information known neither to self nor to others (unknown). 


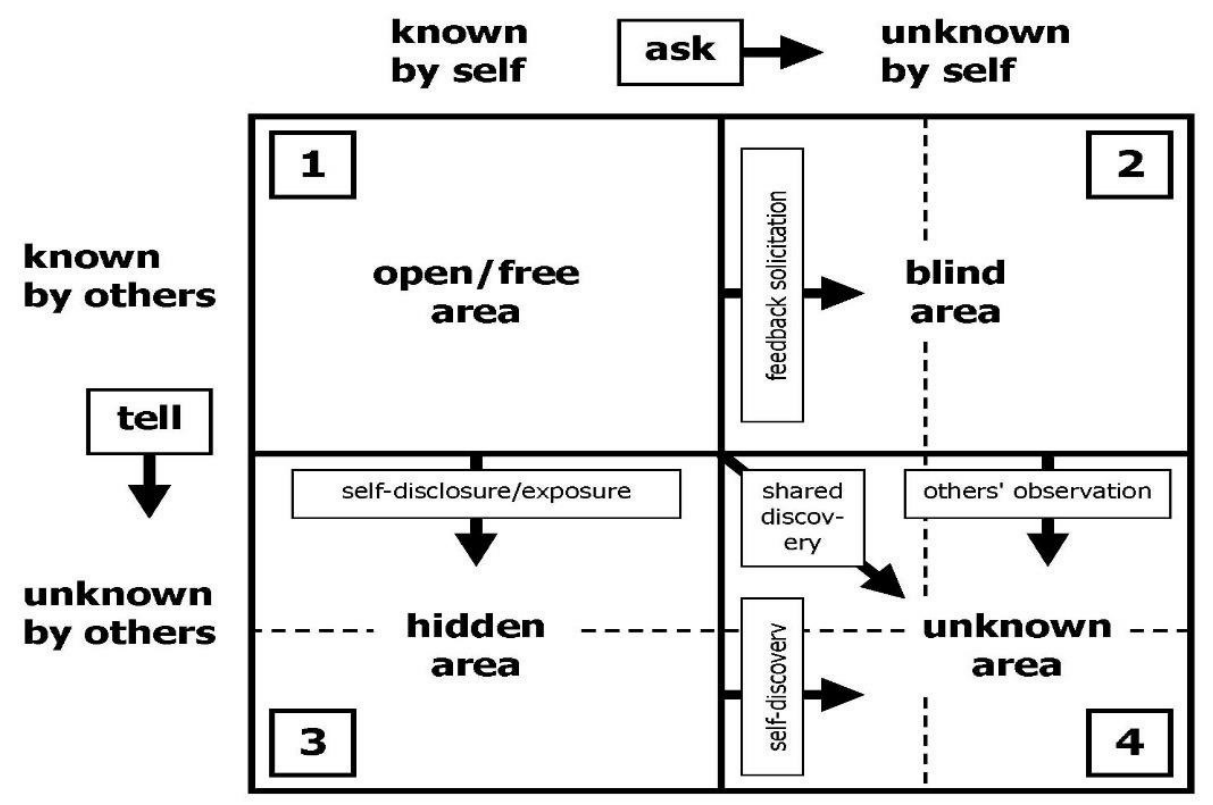

Figure 1. Johari Windows (adopted from Chapman's Design, 2001)

This model is a frequently used pedagogical and research tool by many educators. Wayne (1983) tested the model's reliability and validity on 61 male and 99 female undergraduates from basic communication courses and concluded that the model can be an important pedagogical device if it is accompanied by necessary qualifications.

The notion of this model rests on the perspective that increasing mutual understanding through feedback and disclosure allows an individual to increase the open area and reduce the blind, hidden, and unknown areas of oneself (McShane \& Von Glinow, 2003). In the Johari Window, Luft (1984) argues that for increasing the open area (windowpane 1) an individual and his/her colleagues should be aware of their limitations and work on expanding them. This is done by receiving more feedback from others to decrease one's blind area (windowpane 2) and reduce the hidden area (windowpane 3) through disclosing more about oneself. The combination of feedback and disclosure may also help to produce more information in the unknown area (windowpane 4). The model was adapted by Thurlow, et al. (2004) to provide "a task-based introduction to Computer-Mediated Communication" (p. 103). They applied the model considering multiple learning dimensions when the students experience knowledge as 'Open'/explicit, 'Blind' implicit, 'Hidden' /imbedded and 'Unknown' unconscious/incidental. The term 'Incidental learning' was coined by Kerka (2000) to depict unconscious implicit learning while doing activity not designed as an educational resource. It describes the state when learners move outside their comfort zone and start doing something they are not used to. To address some of the learners' discomfort, tutors could design lessons in which learning happens unconsciously which could benefit the students even more than explicit learning. This incidental learning could be an optimal chance for boosting learners' learning competency, attitude, interpersonal skills, and self-confidence (Morgan, 2011). 
For the sake of the current study, this model was adapted by the researcher to develop AOU students' productive skills through employing the four learning dimensions. The students started by exploring what sort of background knowledge and information about a certain topic/issue is common among them (windowpane 1/explicit learning). Then, they were encouraged to exchange their knowledge and understanding of this topic/issue with their peers to gain more understanding (windowpane $2 /$ implicit learning) and to collaborate together to read about, analyse, interpret and explain a certain topic/issue (windowpane 3/imbedded learning). This helped the students to explore their potential areas of learning and to produce more information in the unknown area maximizing their knowledge acquisition and other interpersonal communication skills (windowpane 4/incidental learning). Thus, the students were able to experience conscious/explicit and uncurious/ incidental learning.

\subsection{Framework}

The conceptual framework of this implementation includes its description, duration, participants, methodology, design, delivery, instruments, assessment, findings and discussion. Each concept is discussed with detailed description in the following sections.

\subsection{Description}

The implementation of this study was administered on four groups of Arab Open University students. They registered in the reading course (EL118) from different programmes (English Language and Literature, Business Administration, and Information Technology and Computing). The implementation aimed to investigate whether there is a correlation between the students' high performance achievement and active participation inside and outside the class due to implementing an interactive approach (present to learn and interactive writing) to develop their productive skills.

\subsection{Duration}

The duration of the implementation was four consecutive semesters. It started in the spring semester of the academic year 2012/2013. The implementation of the study continued through three consecutive semesters till fall semester of the academic year 2014/2015.

\subsection{Participants}

A broad age range was represented in this experiment with the youngest participant being 18 years and the eldest being over 50 years old. The majority of participants were under 30 years of age (79\%). The participants were 105 female students registered in the "Reading Comprehension" course (EL118) from different programmes (English Language and Literature, Business Administration and Information Technology and Computing) during four consecutive semesters. During spring semester of the academic year 2012/2013, the first group of twenty two female students registered in EL118 course. During the academic year 2013/2014, a second group of twenty six female students registered in this course during the fall semester while a third group of twenty nine female students registered in it during spring semester. The fourth group of twenty eight female students registered during fall semester of the academic year 2014/2015. 


\section{Methodology}

The main purpose of this research was to establish an interactive learning environment to develop AOU students' productive skills through giving oral presentations and writing prompts. Moreover, the effect of implementing "Present to Learn Approach" was investigated. An experimental design was selected to detect the improvement of the students' productive skills, if any. A post-experiment questionnaire was conducted to investigate the students' assessment of this experiment and which learning elements were considered to be most helpful in facilitating learning and enriching the targeted productive skills.

Data for this study was developed through a fifty-nine question survey divided into sections completed by sixty-two students from different programmes registered in the elective reading course (EL118) at Arab Open University (AOU), Kuwait Branch over a two-year period (four semesters) from 2012-2014. The questionnaire was designed to test a variety of dimensions of student satisfaction with the course content, instructor, class involvement/engagement, "Present to Learn" approach and general summative assessment of the whole experiment. For the purposes of this paper, the general summative assessment section of the questionnaire was statistically analysed. Students registered in the reading course in four consecutive semesters were chosen to complete the survey and all were given the instrument (questionnaire) by the researcher during final class session of each semester. All surveys distributed in that sessions were completed and the return rate was 100 percent. However, only 54 students of the 105 attended the last session of the four semesters and completed the survey. Anonymity was assured and students were asked to answer questions based on their own educational experience with this course and the applied interactive approach. Only continuing students who participated in the experiment were included and no student completed the survey twice.

\subsection{Design}

The implementation adopted the descriptive design to review and survey previous literature and studies related to its variables (interactive approach and productive skills). A quasi-experimental design was adopted to identify the students' performance in giving oral presentations and writing prompts.

\subsection{Delivery}

An interactive blended learning method for delivery was adopted to cover $25 \%$ of the course content in-class and assign $75 \%$ as self-study activities to be done through "Present to learn" approach in groups. The students were assigned to choose one of the "Writing and Discussion Topics" at the end of each unit and start to read external resources from the e-library, Internet, periodicals, magazines, etc. to collect information, critically analyse what they have read, write prompts (notes, summaries, slides, flip charts, poster, etc.), and finally give an oral presentation in class. The purpose of this approach was to give the student a chance to use the learnt theories, concepts and strategies in a suitable authentic context and to put the vocabulary learnt on a particular topic into real usage (production rather than mere comprehension). 


\subsection{Instrument}

Two main instruments were used to measure the variables of the study. A performance assessment observation checklist was developed to assess the students' oral presentation with the written prompts. In addition, a questionnaire was developed to measure the students' evaluation of the whole experiment such as: assessment of the course content, assessment of teaching methods/strategies/practices, self-assessment on involvement/engagement, reflection on "Presenting to Learn" approach, and general summative assessment

\subsection{Assessment}

The assessment technique used in this experiment is the performance assessment which is a measure of assessment based on authentic tasks such as activities, assignments or tasks that require students to show what they can do. Performance assessment, also known as alternative or authentic assessment, is a form of testing that requires students to perform an authentic task rather than select an answer from a ready-made list, or respond to a certain comprehension question. It is to act upon and bring to completion a certain project or assignment. It involves displaying one's knowledge effectively to bring to completion a complex product or event. It typically involves the creation of products. Brown \& Hudson (1998) illustrate that "performance assessment requires students to accomplish approximations of real-life authentic tasks, usually using the productive skills of speaking or writing" (p.564). Therefore, this assessment technique was used to evaluate the students' oral presentations with written prompts in the form of PowerPoint presentations, role plays, banners/poster, charts, notes, mind maps, summaries, etc.

\section{Findings and Discussion}

Adult non-traditional students reported that they prefer traditional method of giving instructions since they were more familiar with it whereas young adult traditional students preferred the applied interactive writing and presentation approach. Some of the students were not motivated to participate in giving presentations and writing prompts since it was not reflected on their grades. Only 62 female students out of the 105 (59\%) participated in the experiment by working in groups, giving oral presentation and writing prompts while 5 students preferred to work individually.

54 students responded to the questionnaire. The students were asked to provide a brief description to their experience of in-class presentation and interactive writing as a teaching method mentioning the benefits gained from this practice and problems encountered. They have reported that they regularly attended classes $(89 \%)$. They also reported that they have spent an average of 5-6 hours per week doing work outside classroom for this course. $92 \%$ of the students reported that this practice has affected their academic performance positively and helped them in achieving high grades in other AOU courses especially in Oral and Presentation Skills course (EL119). Some of them (57\%) commented that at first they were reluctant to participate in giving presentation, but eventually they succeeded in overcoming their fear and confronting audience. Some students suggested applying this interactive 
approach on literature courses so as to dramatize short stories and plays. Few business students reported that they believe this approach is going to be very beneficial for their career since they will be asked to give presentations for their reports and proposals.

Table 1. Students' Responses to the General Summative Section

\begin{tabular}{llllll}
\hline Criteria Evaluated & $\begin{array}{l}\text { Strongly } \\
\text { Agree }\end{array}$ & Agree & Neutral & Disagree & $\begin{array}{l}\text { Strongly } \\
\text { Disagree }\end{array}$ \\
\hline $\begin{array}{l}\text { 1. the approach is effective in advancing } \\
\text { my oral presentation skills. }\end{array}$ & $80.36 \%$ & $19.64 \%$ & $0.00 \%$ & $0.00 \%$ & $0.00 \%$ \\
$\begin{array}{l}\text { 2. the approach is effective in advancing } \\
\text { my written prompts. }\end{array}$ & $76.00 \%$ & $5.40 \%$ & $18.60 \%$ & $0.00 \%$ & $0.00 \%$ \\
$\begin{array}{l}\text { 3. the approach helped me to work in } \\
\text { groups. }\end{array}$ & $90.74 \%$ & $9.25 \%$ & $0.00 \%$ & $0.00 \%$ & $0.00 \%$ \\
$\begin{array}{l}\text { 4. I rate this approach "Present to Learn" } \\
\text { as an effective teaching/learning method. }\end{array}$ & $81.48 \%$ & $18.52 \%$ & $0.00 \%$ & $0.00 \%$ & $0.00 \%$ \\
$\begin{array}{l}\text { 5. I recommend this course to other } \\
\text { students. }\end{array}$ & $62.96 \%$ & $20.37 \%$ & $16.66 \%$ & $0.00 \%$ & $0.00 \%$ \\
\hline
\end{tabular}

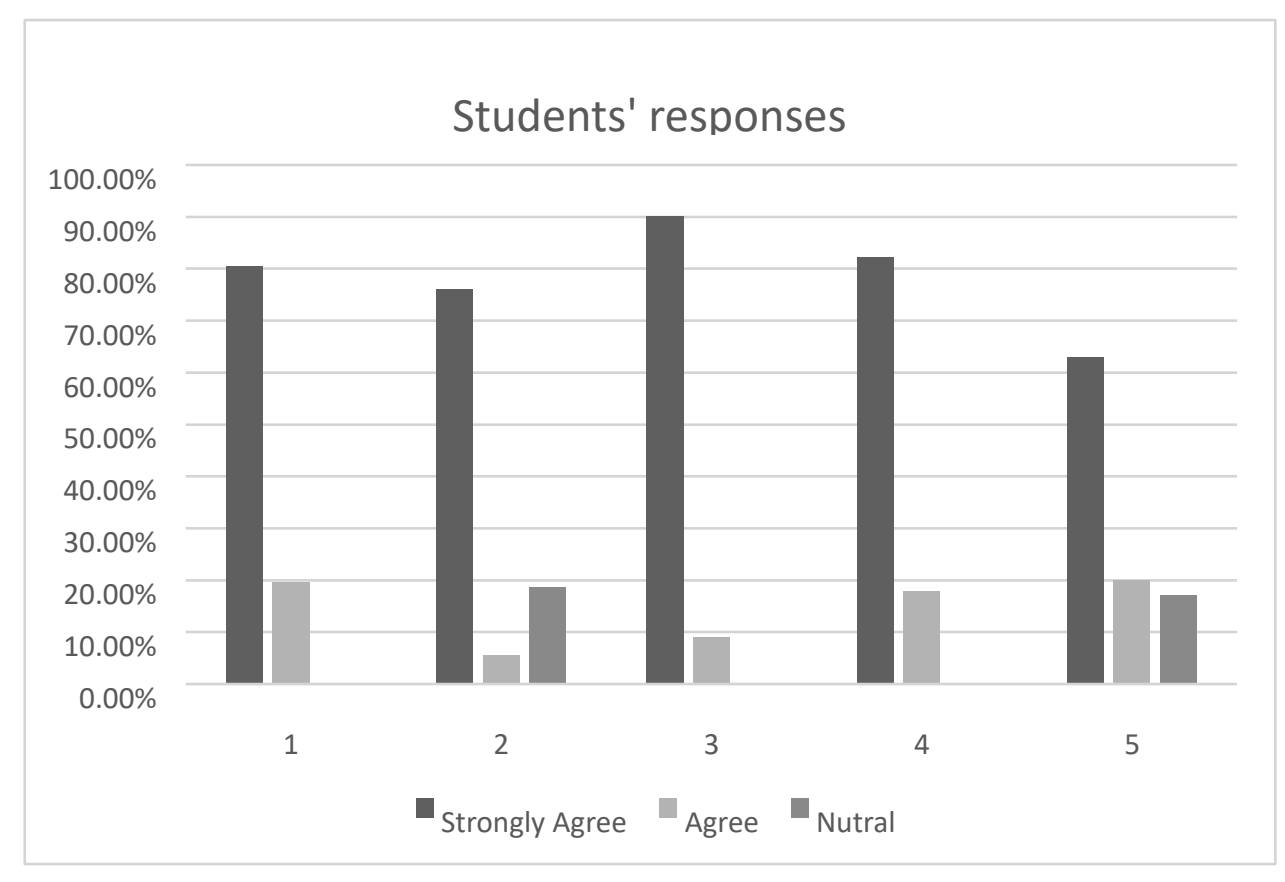

Figure 2. Students' Responses

As shown in the above table, a majority of the students $(80.36 \%)$ strongly agreed that this interactive approach was effective in improving and advancing their oral presentation skills while (19.64\%) of them agreed to the same item. In addition, (76\%) of the students strongly 
agreed that this interactive approach was effective in improving and advancing their written prompts while $(18.60 \%)$ of them were neutral to the same item. No one has reported that this approach was ineffective in advancing their oral presentation skills and written prompts. Forty nine students $(90.74 \%)$ strongly agreed that this approach helped them to work in groups inside and outside the campus. Some of them reported that they established a group on WhatsApp to communicate together and used emails to send links and websites for external readings relevant to the presented topic. Forty four students $(81.48 \%)$ considered "Present to Learn" approach as an effective teaching/learning method. 34 students (62.96\%) strongly recommended this course to other students while 9 students $(16.66 \%)$ were natural towards this recommendation. Some comments were gathered from students' responses to few reflection questions about what they liked most and least, what should be left or changed when repeating the course and what other learning needs they wish to share. Some of these comments were "The things I liked most were class discussions and building an argument when trying to deliver a message or a concept", "The things I likes least were course timing mostly, and sometimes group work was challenging as we had busy schedules with work and study", and "I would like to have Art appreciation classes." The results have shown that students who participated in interactive writing and presentations to reflect their group work $(54.2 \%)$ obtained higher grades in their overall course assessment than those who preferred to work alone $(4.7 \%)$ and those who failed to work with others and did not give any presentations $(40.9 \%)$. Almost all the students who failed the course throughout the four semesters $(13.3 \%)$ did not participant in the experiment except for two failure cases $(1.9 \%)$ who participated in group work and oral presentation yet skipped many classes and failed the course.

\section{Discussion}

The exploratory survey of a "Present to Learn" interactive approach and its effects on enhancing students' productive skills yielded some interesting and useful results. In many ways, these results were in keeping with the pre-set perceptions of students' interaction and overall course satisfaction. Students were overall generally satisfied with their oral presentation and interactive writing experience. However, it was noticed that more non-traditional adult students were less satisfied with this interactive approach than their traditional young adult colleagues, even though this difference is small, this was reflected on not participating in oral presentations and class engagement. This result was somewhat expected since more non-traditional adult students are more likely to be familiar with and prefer regular classroom instruction without giving some room for brainstorming, discussion and real production.

It was observed that cooperative work especially with having critical partners who challenge other students' presented ideas and interpretations has improved the students' productive skills through learning from each other in one group and competing with other groups. The collected feedback from the questionnaire was in favour of applying "Present to Learn" approach on more groups which was implemented across three consecutive academic 
semesters. Moreover, the students' end results of the overall course assessment (Mid-Term Assessment (MTA), Tutor Marked Assignment (TMA) and final exams) were statistically analysed and a correlation between high performance achievement and active participation inside and outside the class was drawn.

\section{Conclusion}

The findings of this study are consistent with the overall level of satisfaction with the interactive approach, but appears to indicate that non-traditional adult students who prefer traditional instruction methods are somewhat less satisfied with the oral presentations and group work employed in blended course formats. It was believed that traditional younger students would feel overwhelmed or intimidated by more experienced adult students and/or perhaps do not fully recognize the usefulness of classroom interaction. However, the results have proven that this belief was wrong. Traditional younger students who preferred non-traditional methods of instruction were more satisfied with the applied interactive approach "present to Learn" and have reported that this experiment has given them a chance to explore and express their opinions, interpretations, analysis and reflection in an encouraging classroom environment (windowpane 1). They also reported that they have learned a lot from this cooperation and their collaborative efforts (windowpane $2 \& 3$ ). The incidental/accidental learning dimension was clearly represented in this experiment hence the majority of the students reported that this experiment has helped them in broadening their knowledge, improving their communication skills, advancing their interpersonal skills, increasing their interest in the field of study and enhancing their professional expertise (windowpane 4). This is in addition to improving and enhancing the targeted productive skills such as giving oral presentation, taking notes, writing summaries, designing posters and charts and writing PowerPoint presentation slides. The majority of the students reported that this approach has enhanced their academic, professional and personal practices.

\section{References}

Bradwell, P. (2009). The Edgeless University. Magdalen House, London: UK. ISBN 978-1-90669316-9.

Brown, J. D., \& Hudson, T. (1998). Alternatives in Assessment. TESOL Quarterly, 32(4), 653-675. https://doi.org/10.2307/3587999

Chapman, A. (2001). Adaptation, review and code based on Ingham and Luft's original johari window concept. Retrieved December, 2010 from http://postdoc.hms.harvard.edu/slides/AliceSapienzaJohari\%20window\%20model.pdf?v $=\{0 \mathrm{~B} 58 \mathrm{~B} 4 \mathrm{E} 7-\mathrm{CB} 55-4930-9157-\mathrm{D} 4 \mathrm{~A} 588 \mathrm{BCBC} 85\}$

Kerka, S. (2000). Incidental learning: Trends and issues. Alert no. 18, Washington, DC: ERIC Clearinghouse of Languages and Linguistics, ERIC Digest ED446234 Retrieved September, 2011 from http://ericdigest.com 
Knowles, M., Holton, E. F., \& Swanson, R. A. (2005). The adult learner: The definitive classic in adult education and human resource development. Burlington, MA: Elsevier. https://doi.org/10.4324/9780080481913

Luft, J. (1984). Group processes: An introduction to group dynamics (3rd ed.). Palo Alto: Mayfield.

McShane, S. L., \& Von Glinow, M. A. (2003). Organizational behavior: Emerging realities for the workplace revolution (2nd ed.). Boston: McGraw-Hill.

Morgan, L. (2011). Harmonious learning: Yoga in the English language classroom. English Teaching Forum, 49(4), 2-13.

Paul, J., \& Mark, B. (2002). An interactive, students-centred approach, adopting the SOLO taxonomy, for learning to analyse laboratory data in veterinary clinical pathology. UTP Journals. Retrieved December, 2013 from http://www.utpjournals.com/jvme/tocs/291/56.pdf

Picciano, A. G. (2009). Blending with purpose: The multimodal model. Journal of the Research Centre for Educational Technology, 5(1), 4-14.

Swartz, S. L., Klein, A. F., \& Shook, R. E. (2001). Interactive writing and interactive editing. Carlsbad, CA: Dominie Press. Retrieved November, 2013 from http://stanswartz.com/collaboration.html

Thurlow, C., Lengel, L., \& Tomic, A. (2004). Computer mediated communication: Social interaction and the internet. London: Sage Publications Ltd. Retrieved December, 2010 from http://www.tandfonline.com/doi/abs/10.1080/15358590600763565

Vygotsky, L. S. (1986). Thought and language. Cambridge, MA: MIT Press.

Wayne, H. (1983). An Examination of the Johari Window as a Research tool and a theoretical model. Online Submission, ERIC Number: ED238039. Retrieved November, 2013 from http://eric.ed.gov/?id=ED238039

\section{Copyright Disclaimer}

Copyright for this article is retained by the author(s), with first publication rights granted to the journal.

This is an open-access article distributed under the terms and conditions of the Creative Commons Attribution license (http://creativecommons.org/licenses/by/3.0/). 